\title{
Health Workers' Perceived Challenges \\ for Dengue Prevention and Controll in the Dominican Republic
}

\author{
Bienvenido A. Veras-Estévez MD MPH and Helena J. Chapman MD MPH PhD
}

\begin{abstract}
INTRODUCTION Mosquito-transmitted dengue remains an endemic threat to population health in various tropical and subtropical regions. Recommended dengue prevention practices focus on vector control and reducing human-mosquito interactions, by practices such as removing standing water, wearing protective clothing and using repellent, as well as seeking medical care when symptomatic. Health workers in the community educate and empower citizens about recommended prevention practices, and thus are indispensable in implementing national dengue initiatives at the local level. However, their health messages may not resonate with all community members, resulting in low adherence to recommended prevention practices. Understanding the factors associated with low adherence to dengue prevention and control measures is essential for strengthening national dengue initiatives.
\end{abstract}

OBJECTIVE Identify health workers' perceived challenges for dengue prevention and control strategies and describe their recommendations for strengthening dengue control in the Dominican Republic.

METHODS From January through March 2005, a qualitative study was conducted in five provinces of the Dominican Republic. Based on literature review and consultations with clinical specialists, a semistructured interview guide of nine questions was designed. A purposive sample of 19 health workers (10 men, 9 women) was interviewed, including public health practitioners, entomologists,

\section{INTRODUCTION}

Dengue is the most important mosquito-borne viral infection across the globe, with approximately 50-100 million cases annually.[1] Novel modeling and mapping frameworks have placed estimated dengue burden at 390 million infections and 96 million clinical cases annually, with almost 4 billion people at risk in 128 countries in tropical and subtropical geographic regions.[2,3] Four serotypes of dengue virus (DENV 1-4) may be transmitted by the primary vector, the female Aedes aegypti mosquito. Infection with one DENV strain confers permanent immunity to that strain, but provides limited protection against subsequent infection by other strains.[4]

Following World War II, in the 1950s and 1960s, A. aegypti eradication programs in the Americas Region were effective in controlling the spread of yellow fever and dengue.[5] However, after vector control programs were discontinued in the late 1960s, A. aegypti reemerged in the Region and expanded its distribution.[6] International population movement and trade facilitated air and sea transport of people and animals as well as A. aegypti vectors. [7,8] Also, increased human population density and expanded urbanization to "megacities," along with limited vector surveillance programs, created an ideal environment for continued arbovirus transmission.[9] Geographic spread and reinfestation of Aedes vectors in the Americas and lack of sustainable vector control programs have continued into the $21 \mathrm{st}$ century. educators, clinicians and an administrator. Question topics included occupational experiences in dengue prevention and control; views on vector control in communities; perceived challenges for citizens' adherence to recommended practices; and suggested measures for strengthening adherence to vector control at local and national levels. Thematic analysis was used to identify salient themes.

RESULTS Health workers described the following perceived challenges: 1) limited individual economic resources; 2) individual lack of awareness, education or action; 3) limited cohesion among community members; and 4) limitations in sustainability of government interventions. They made 14 recommendations related to the 4 perceived challenges.

CONCLUSIONS These findings evince the complex interplay of economic, environmental, health, political and social factors that can directly or indirectly influence individual and community adherence to recommended dengue prevention measures. By understanding how these intrinsic and extrinsic factors hinder adherence, health authorities can adapt national policies to strengthen community participatory action in vector control, empower leadership potential by health workers and community members, and provide an appropriate systemic approach to preventing disease transmission.

KEYWORDS: Dengue, dengue virus, arbovirus, community health, prevention, control, communicable disease control, qualitative research, Dominican Republic

Traditional vertical or "top-down" vector control strategies, including government-run pesticide spraying, initially showed promising results in global mosquito control, but lacked sustainable funding over time.[10] These were followed by a transition to horizontal or "bottom-up" approaches that took into account multiple factors associated with DENV transmission and employed integrated, community-based strategies for health education and promotion, based on community empowerment and collaboration among stakeholders directly and indirectly involved in vector control.[11] Health education campaigns that have emphasized recommended vector control practices and active participation by community members in reducing Aedes populations in and around their homes have been shown to increase knowledge and awareness of dengue, but knowledge does not necessarily equal action.[12] Innovative approaches can integrate dengue prevention and control strategies-sustaining political support, forming community-based partnerships, strengthening active epidemiological surveillance programs, and building empowered communities - to promote long-term vector control and community behavioral changes. As observed in Cuba, intersectoral collaboration and community participation, coupled with political will, are bulwarks of dengue prevention and control strategies.[13]

In 2012, WHO developed an operational framework for integrated vector management strategies incorporating five elements: 1) advocacy, social mobilization and legislation (e.g., policy 
development, community empowerment); 2) collaboration within the health sector and with other sectors (e.g., enhanced communication among stakeholders); 3) an integrated approach (e.g., use of resources for multiple diseases or methods); 4) evidence-based decision-making (e.g., application of scientific findings to practice); and 5) capacity-building (e.g., provision of resources to manage strategies).[14] Health workers (HWs) play an indispensable role in implementing national initiatives at the local level.[15] In integrated dengue prevention and control strategies, HWs serve in various capacities to educate community members about the threat of DENV infection and actions to improve compliance with vector control recommendations in and around their homes.

The Dominican Republic (DR) is an upper-middle-income country with rapid population growth and increasing poverty rates. The population of 8.6 million habitants in 2000 , with $32 \%$ of DR citizens living at or below the poverty threshold, increased to 9.9 million habitants in 2010 , with $41.6 \%$ living at or below the poverty threshold.[16] Although approximately $98 \%$ of the population has access to electricity,[16] households typically do not have consistent 24-hour service, and thus must store water for family use in large tanks inside or outside the home.[17]

To address this challenge, PAHO and the DR Ministry of Health and Welfare (MISPAS) developed the National Strategy for Integrated Dengue Prevention and Control, which proposed five specific actions for entomology: 1) conduct operational research; 2) incorporate areas for applying innovative techniques by personnel trained in vector control; 3) promote collaborative training for all vector control personnel; 4) strengthen the overall structure of the vector control program and affiliated laboratories; and 5) implement timely biological, chemical and physical vector control strategies in prioritized areas.[18] One example of a physical or environmental vector control strategy in the DR was the traditional national campaign, Cloro Untado, Tanque Tapado (chlorine applied, tanks covered), which focused on HW-led community participatory action in vector control, and was widely disseminated by radio and television announcements. This campaign aimed to teach community members and school children the importance of using chlorinesoaked cloths to coat the inside surfaces of water storage tanks, and most importantly, covering all water storage containers, to reduce potential mosquito breeding sites.[19] symptoms). Evidence of cohesive community action has been observed in two Latin American countries. Cuba's health system emphasizes national promotion of healthy behaviors, such as vector control and immunization practices, through active leadership by families and communities.[21] Argentina's health system has highlighted the need for cohesion and progress to reach specific health goals, empowering community members to be active and responsible stakeholders in decision-making about vector control.[22]

There are high hopes for the first licensed dengue vaccine and other vaccine candidates,[23] but it is still critically important to better understand behavioral, environmental and socioeconomic factors that may increase the number of mosquito breeding sites in and around homes, and thus risk of DENV infection. With the complex dynamics of dengue prevention and control strategies in the DR, HWs can encounter challenges in adherence to recommended vector control measures among community members.

This study's objective was to identify HWs' perceived challenges for dengue prevention and control strategies, using a qualitative approach, and describe their recommendations for strengthening future actions for dengue control in DR communities.

\section{METHODS}

Study type, setting and sample From January through March 2005, a qualitative study using an ethnographic approach[24] was conducted in municipalities of five DR provinces: Jarabacoa in La Vega Province; Baní in Peravia Province; San Felipe in Puerto Plata Province; Navarrete, Sabana Iglesias, Tamboril, Villa González and Santiago de los Caballeros, in Santiago de los Caballeros Province; and Santo Domingo, in the National District of the same name. These municipalities were selected because epidemiologic surveillance found laboratory-confirmed cases of dengue there. Table 1 presents the demographic and epidemiologic characteristics of study sites.

Inclusion criteria Individuals included were HWs who had specific responsibilities or leadership roles in implementing dengue prevention and control during endemic or epidemic periods, had clinical or other expertise in dengue prevention and control, and recognized dengue burden in their local community or the DR.
To improve early dengue case identification and reporting, MIS-PAS established a passive dengue surveillance system, located in the departments of epidemiology in designated health centers.[20] However, it is not known how much reported surveillance data help promote community leadership (e.g., juntas de vecinos- neighborhood councils-and nongovernmental organizations) or stimulate development of health interventions to disseminate health information (e.g., reduce standing water, identify disease
Table 1: Demographic and epidemiologic characteristics of study sites by municipality

\begin{tabular}{|c|c|c|c|c|c|}
\hline \multirow{2}{*}{ Province } & \multirow{2}{*}{ Municipality } & \multicolumn{3}{|c|}{ Population $^{\mathrm{a}}$} & \multirow{2}{*}{$\begin{array}{c}\text { Dengue } \\
\text { cases, 2004 }\end{array}$} \\
\hline & & Total & Male & Female & \\
\hline La Vega & Jarabacoa & 56,931 & 29,075 & 27,856 & 43 \\
\hline Peravia & Baní & 107,926 & 52,897 & 55,029 & 105 \\
\hline Puerto Plata & San Felipe & 146,882 & 72,295 & 74,587 & 123 \\
\hline \multirow{5}{*}{ Santiago } & Sabana Iglesias & 12,232 & 6,289 & 5,943 & 12 \\
\hline & Villa González & 29,126 & 14,761 & 14,365 & 17 \\
\hline & Navarrete & 42,210 & 21,204 & 21,006 & 16 \\
\hline & Tamboril & 49,810 & 24,863 & 24,947 & 14 \\
\hline & Santiago de los Caballeros & 622,101 & 302,619 & 319,482 & 319 \\
\hline National District & Santo Domingo & 913,540 & 430,698 & 482,842 & 273 \\
\hline
\end{tabular}

Sources: ${ }^{a}$ Dominican Republic National Statistics Office. VIII National Census of Population and Housing, 2002. Santo Domingo; Dominican Republic National Office of Statistics; 2002. Available from: https://www.one.gob.do/Estadisticas/263/ poblacion-y-vivienda. ${ }^{b}$ Dominican Republic Ministry of Health Department of Epidemiology, Summary of Dengue Cases by Municipality and Province, 2004 (Unpublished). 
Exclusion criteria HWs were excluded who showed no interest in dengue burden in their local community or nation or did not want to participate in this study.

Researchers recruited a purposive sample of $19 \mathrm{HWs}$ (10 men, 9 women), up to 5 individuals in each province, based on referrals from administrative or clinical experts at provincial or regional health centers. The sample included public health practitioners, entomologists, educators, clinicians and an administrator. Table 2 displays study participants' demographic characteristics.

Data collection Using a socioecological framework to guide study design, methods and analysis,[25] we developed a semistructured interview guide of nine questions to facilitate discussion with participants. Interview questions were prepared in English, translated into Spanish, and verified by a bilingual Dominican physician. Stem interview questions are displayed in Appendix 1. We defined perceived challenges according to the health belief model, a health behavior model that aims to explain health behavior based on individuals' attitudes and beliefs about factors that enable or hinder them from completing specific actions.[26] Based on literature review and consultations with clinical specialists, question topics included 1) occupational experiences in dengue prevention and control, 2) views on vector control in communities, 3) perceived challenges for community members' compliance with recommended practices, and 4) recommendations to strengthen adherence to vector control strategies at local and national levels.

Interviews were conducted in two steps. First, participants were asked to describe their educational and professional responsibilities in their community. Second, participants were asked to respond to nine questions about their experiences and perceptions of dengue prevention and control (Appendix 1). Interviews used probing techniques to encourage participants to elaborate.[27] Interviews were conducted in Spanish in a quiet area in the community or a closed office in the local health clinic. The length of each interview depended on how extensively participants elaborated on responses. Interviews were digitally recorded, and after each, researchers prepared field notes by hand, including participant observations, informal dialogue with participants, and a daily log of time schedules.[27] Data collection was concluded when data saturation was reached, i.e., no new themes emerged.[28]

Analysis Interview data and field notes were transcribed and deidentified by the second author and verified by the first author.
Prior to beginning data collection, we used scientific literature and previous experiences in community health campaigns to develop preliminary categories. After in-depth coding of interview transcripts by each researcher, we conferred to discuss coded nodes. Discrepancies in coding procedures were discussed in order to improve interobserver reliability. Using thematic analysis, we reviewed the final coded nodes and reached conclusions on major emerging themes.[29,30] Card sorting (using cards to organize topics into general categories) and peer debriefing (seeking feedback or critique from colleagues not involved in the study and therefore unlikely to be biased) techniques were used to enhance validity and reliability.[29,31]

Ethics The study was approved by the institutional review boards of the University of Florida (Gainesville, USA) and the Hospital Regional Universitario José María Cabral y Báez (HRUJMCB) (Santiago de los Caballeros, DR). Participation was voluntary and required written informed consent.

\section{RESULTS}

Semistructured interviews lasted between 5 and 18 minutes. Perceived challenges included 1) limited individual economic resources, 2) lack of individual awareness, education or action, 3) limited cohesion among community members, and 4) limited sustainability of government interventions. Figure 1 displays a conceptual model based on salient themes.

Limited individual economic resources Most participants expressed that community members' limited economic resources 
Figure 1: Conceptual model of health workers' perceived challenges to community members' adherence to dengue prevention and control measures

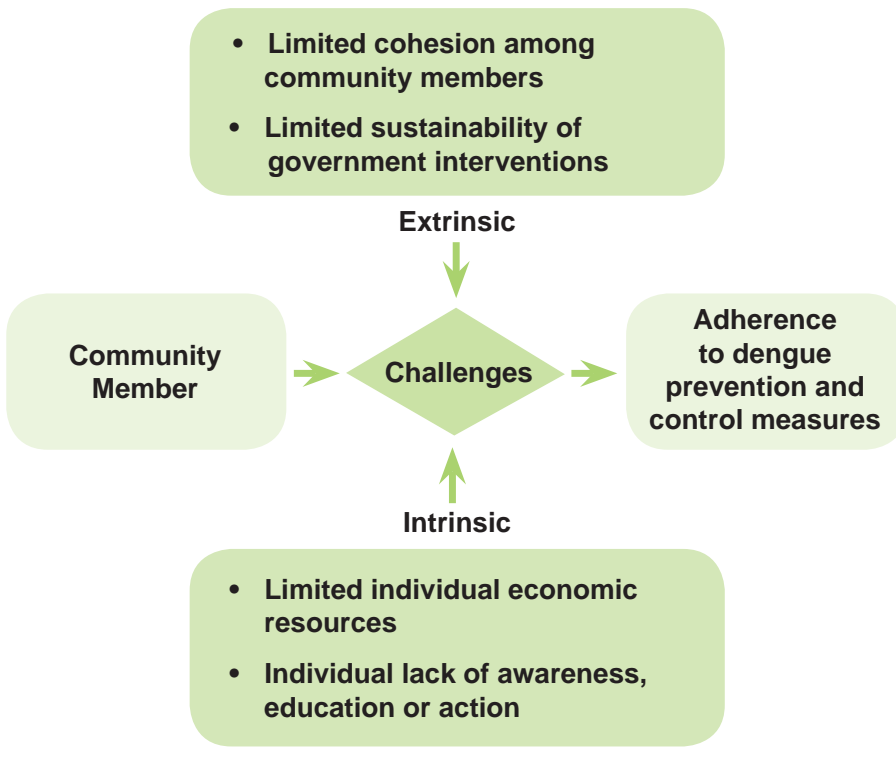

can directly influence adherence to recommended strategies for dengue prevention and control. One participant shared the belief that community members may become disheartened when families must prioritize how their monthly income is used:

They [people] want to protect themselves, but they cannot because they are poor, ... have three children, ... husband works only a little. . . . [and] the small amount that he earns goes to supporting his family. There are not enough funds to spend on mosquito nets or other methods to protect themselves from mosquitoes. (Participant 5, epidemiology coordinator)

Some participants described challenges community members with limited economic resources have in setting priorities among daily activities and expenses. One participant stated:

People have many other worries and often forget about local measures they should use for dengue [prevention and control]. ... They have many other problems to resolve, and this is just one more. (Participant 9, infectious disease specialist)

Another participant commented that his daily wages are approximately RD\$150-\$200, equivalent to US\$4-\$5, which he needs to spend on food for his family. Thus, purchasing insect repellent represents a substantial proportion of his household income (a situation that could be shared by many community members):

Repellent can now cost you . . . the equivalent of RD\$100, which is almost half someone's daily income. (Participant 16, biology and chemistry teacher)

Participants also shared that, although community members are informed about dengue, geographic distance from health institutions can be an obstacle to health care service access. One participant stated that delay in seeking health care services can influence poor health outcomes:

Sometimes, it is difficult for people who live in the communities to seek medical care. They leave everything for the last moment, and when they get to the hospital, they have advanced disease. (Participant 7, entomology technician)
In addition to geographic distance from health institutions, participants described the social context and poor plumbing infrastructure, where community members must constantly store water for household use. One male participant mentioned:

There are communities that do not have indoor plumbing and they must store water, or if they have household plumbing, then water may not arrive for several days. . . . It is also a social problem, not having household plumbing, having to store water, and storing water without proper protection. (Participant 9, infectious disease specialist)

Lack of awareness, education or action by individuals Most participants reported that MISPAS representatives have conducted health seminars about dengue in local communities, recognizing that community members should be aware of recommended strategies to prevent and control mosquitoes in and around their households. One female participant lauded these educational campaigns:

We are more aware and these health seminars have provided knowledge for us to better protect ourselves from other diseases. (Participant 18, educator)

In contrast, one participant stated that some community members who participated in these health seminars still believe that mosquito-transmitted DENV infection is a myth, stating:

There are people who ignore mosquito bites. They think that people are not infected [with dengue] by mosquitoes . . . [but] the concept of mosquitoes [as vectors] has been proven. (Participant 7 , entomology technician)

Another participant went on to relate that community members really do understand dengue as a health threat, but are apathetic. He stated:

Many people do not use prevention measures, ... not because of ignorance, but rather laziness. We have all heard or seen news about dengue on TV, at church, at neighborhood councils and during home visits. (Participant 5, epidemiology coordinator)

Another participant described adherence to recommended measures immediately after a dengue case appears, but then declining over time and eventually disappearing:

People only become scared when they see a close [dengue] case or someone dies, but after that, unfortunately, it [the health message] goes in one ear and out the other. (Participant 9, infectious disease specialist)

Limited cohesion among community members Many participants said that the ideal situation is when community members join forces to combat a disease threat. For example, one participant mentioned:

When a [dengue] case happens, we join as a community, as friends and neighbors, as the neighborhood council. We always live in communities here, we meet, and so we are always together with one another and resolve any issues. (Participant 19, director, neighborhood council)

However, one participant clearly stated that there are limitations in such ideal cohesive action:

This small town is also waiting for the state to resolve this [dengue] problem for them. (Participant 9, infectious disease specialist). 
Some participants mentioned that national dengue initiatives need to come down to the community level, to enhance community preparedness. One participant emphasized the key element of collaborative action:

This is not only a problem of the state. The community must become [actively] involved. If the community does not become [actively] involved, become aware and take collective measures, we will not accomplish anything. (Participant 9, infectious disease specialist)

Another participant stated that educating community members has resulted in a shared sense of responsibility:

We try to advise people, to inform them and educate them that this is not only a problem for the community [as a whole] but rather for everyone [as individuals]. (Participant 7, entomology technician)

Participants stated that mosquitoes can fly from house to house, which makes vector control a challenge. One participant said one person's adherence to recommended measures might be offset by neighbor's lack of adherence, using her own experience as an example:

When I leave my house and I cover and place chlorine in the water tanks, yet perhaps sometimes my neighbors do not [use prevention measures]. In my house, there are no mosquitoes, but beside my house, there are mosquitoes. It [dengue] cannot be controlled because the mosquito flies from one house to another. (Participant 18, educator)

Another participant echoed this challenge:

You do not accomplish anything by individually using prevention measures if the entire community does not perform these tasks. (Participant 9, infectious disease physician)

Limited sustainability of government interventions Many participants reported that MISPAS does not provide a sufficient workforce to educate and empower community members about adherence to recommended dengue prevention measures or economic support to obtain the necessary resources for local distribution. One male participant stated:

Right now, I would like to work [as a health inspector], but I do not have transportation . . . [so] sometimes I have to walk from home. (Participant 6, epidemiology coordinator)

Another participant mentioned that federal support has transitioned in priority from active surveillance to health promotion, stating:

Unfortunately, there is no one in this community who worries about resource allocation for active [dengue] surveillance. In the past, they conducted surveillance in the communities. Now, they visit each house but their messages focus on community prevention. (Participant 5, epidemiology coordinator)

This description of lack of sustainable dengue programs at the community level comes from anotherparticipant:

I worry a lot, since local levels, provinces and local community health clinics have still not developed or implemented a local plan for dengue prevention and control. They are not energized to act. . . To avoid [future] cases, we need to create a permanent mechanism for [dengue] prevention and control. (Participant 13, entomology service director)
Another male participant mentioned that a main limitation of the dengue surveillance system is lack of clinical preparedness for differential diagnosis between dengue and dengue-like clinical presentations:

[It's not clear] whether [registered] dengue cases actually reflect true dengue cases, since we receive reports of dengue that are not true dengue cases, ... so we have to be careful. We should urge the Ministry of Health to recognize that the registry is not adequate. (Participant 9, infectious disease specialist)

Recommendations Table 3 displays HWs' identified challenges and related recommendations for improving community members' adherence to dengue prevention and control measures.

\section{DISCUSSION}

This is the first known study to describe how HWs perceive community members' adherence to recommended local dengue prevention and control measures in the DR. Although several years have passed since data collection, we decided to publish this article because the study objective remains relevant and timely in light of emerging epidemics of four arboviral infections in Latin America and the Caribbean (DENV, chikungunya, Zika and Mayaro).[32-35] HWs carry out multiple responsibilities in vector control in their respective municipalities in the five provinces, and their voices are essential to inform stakeholders about observed gaps in delivery of health education programs and health care services in their communities. Given current and future threats of arboviral disease transmission in Latin America and the Caribbean, we believe that these study findings can be instrumental in better understanding challenges to strengthened community participatory action in vector control in the DR.

Dengue became a mandatory reportable disease in the DR in 1995, and MISPAS's surveillance system was reestablished in 1997, enforcing active case finding, and revised in 2000 , facilitating community-based participation for dengue control, such as the Cloro Untado, Tanque Tapado initiative.[35] PAHO leadership adopted Resolution CD43.R4 in 2001, emphasizing dengue's increasing burden and health threat in the Americas Region. [18] Over time, DR national priorities for dengue prevention and control have evolved, including a proposal for additional training of HWs at municipal and provincial levels.[18] The leadership role of HWs in local communities, however, has been undervalued as an essential component for community education and empowerment for adherence to recommended dengue preventive measures, both in the DR and globally.[36,37]

In this study, participants described intrinsic challenges they considered obstacles to community members' adherence to recommended measures. They mentioned that community members appeared to prioritize other work or domestic responsibilities over vector control. Since many preventive measures are cost-free, such as removing standing water in and around the household, two factors will continue to challenge how HWs educate and empower community members in understanding dengue's severity. First, daily life in the DR involves high temperatures and humidity, inconsistent electricity services, and need for water storage in large plastic or metal tanks.[17] Thus, living daily with mosquitoes becomes the norm and can create a false sense of invincibility to dengue or other mosquitotransmitted diseases.[38] Second, how community members 
Table 3: Health workers' recommendations for improving community adherence to dengue prevention and control measures

\begin{tabular}{|l|l|}
\hline Perceived challenge & Recommendation \\
\hline $\begin{array}{l}\text { Increase access to (and number of) educational } \\
\text { programs for community members, adapting a } \\
\text { "train the trainer" approach }\end{array}$ \\
$\begin{array}{l}\text { Implement sustainable educational programs for } \\
\text { community members that emphasize key health } \\
\text { facts and motivate their adherence to prevention } \\
\text { measures }\end{array}$ \\
\hline Limited individual &
\end{tabular}

\section{Illustrative quote}

"It is not only about publishing news or distributing pamphlets to people. You have to make sure that people learn. You should be there, sit next to them, explain, and show them cases." (Participant 10 , primary care physician)

"If it is a poor neighborhood with unsanitary conditions ... we can say that the people live in extreme poverty and cannot take care of themselves well ... they leave everything for the last moment... sometimes there is nothing ... and many times when there is no solution, it is too late to take care of the patient." (Participant 7, entomology technician)

"If people have [knowledge about dengue], but do not have the Facilitate widespread distribution of chlorine for prevention measures, as a local impact strategy economic resources, they will not be able to obtain the means [for prevention measures] to protect themselves." (Participant 5, epidemiology coordinator)

Offer community members other prevention means at little or no cost

Emphasize HWs' essential roles in community education and follow-up for dengue prevention and control

Lack of individual awareness, education or action

Highlight use of innovative health promotion strategies to disseminate health messages via $\mathrm{TV}$, radio and social media

Promote individuals' moral responsibility as community members to educate by example

Empower community members to understand their influence through sustainable collective action

Limited cohesion among community members
"For example, sleeping covered up with clothing [and sheets], not letting mosquitoes bite you." (Participant 8 , laboratory technician)

"I think that community health educators are the most important sources of information, constant information. Sometimes, because they work right in the community, they can bring the health message directly. They do not just preach what to do, but they serve as an example. This is not the same as a health worker or educator who works in a community or neighborhood and presents a health seminar about a prevention measure but does nothing." (Participant 9, infectious disease specialist)

"It is a [TV or radio] commercial that is directed to the entire population, where everyone can understand the message and can help to prevent dengue." (Participant 11, health promoter)

"Home measures. . . if we complete all the domestic tasks [recommended for dengue prevention] and each person is responsible for his or her own house, then I believe that [through] all these things that we are talking about, from the collective point of view, we can eliminate mosquitoes and dengue." (Participant 9 , infectious disease specialist)

"We shouldn't wait for someone to become sick before we teach people about dengue. We have to take the initiative and teach our community how to prevent it. We should all take into account the fundamental importance of public health education. ...., Dominican physicians should take leadership on this issue because it affects the whole society." (Participant 10, primary care physician)

"Perhaps to involve the churches because people hear so much and the voice of the churches is followed. . if preaching the [gospel] word also incorporates some [dengue] prevention measures, I think that would help people in the congregation . . that at least one or two family members will attend the church service and hear the [health] message, and perhaps can promote this health information and collectively impact the community." (Participant 9, infectious disease specialist) 


\begin{tabular}{|c|c|}
\hline \multirow{4}{*}{$\begin{array}{l}\text { Limited sustainability of } \\
\text { government interventions }\end{array}$} & $\begin{array}{l}\text { Expand coverage of dengue prevention } \\
\text { programs (e.g., youth groups, organizations for } \\
\text { mothers, other associations) }\end{array}$ \\
\hline & $\begin{array}{l}\text { Identify limitations in local and national surveil- } \\
\text { lance and diagnostic systems to serve as a } \\
\text { framework for future action }\end{array}$ \\
\hline & $\begin{array}{l}\text { Strengthen local level support by increasing the } \\
\text { number of health workers }\end{array}$ \\
\hline & $\begin{array}{l}\text { Provide incentives to health workers through } \\
\text { economic resources and continuing education } \\
\text { opportunities }\end{array}$ \\
\hline
\end{tabular}

"These people [health promoters] dedicate their time to meet with youth groups, organizations for mothers, other associations. . . . They dedicate time to health education and promotion of prevention strategies, teaching about dengue, distributing brochures, and sharing videos and movies. We have observed that this initiative has provided positive results." (Participant 14, supervisor, Dengue Prevention and Control Program)

"I believe that there's probably a divide among primary care, notification and surveillance that has to be overcome for the program to proceed adequately with trustworthy statistics." (Participant 9, infectious disease specialist)

"This is a very poor province. We do not have sufficient health personnel for patient followup, so we try to organize things and prevent [dengue transmission] because we face a big challenge in clinical care." (Participant 14, supervisor, Dengue Prevention and Control Program)

"Sometimes I have to use my personal funds to pay for transportation by motorcycle because I believe in public health and try to help. We need to have more support so that we can work [as health promoters] in these communities." (Participant 6, epidemiology coordinator)

perceive disease risk is intimately linked with the perceived benefits of investing energy and time in consistent use of recommended vector control practices at home.[39] Since the clinical spectrum of dengue infection runs from nonsevere (e.g., asymptomatic, cold-like symptoms) to severe (e.g., hemorrhage),[40] people's understanding of the disease can influence health-seeking behaviors.[38,39] Moreover, without a solid and comprehensive understanding of dengue severity and other disease threats at the community level, erroneous risk awareness and poor preventive practices will prevail, impeding advances in national priorities for dengue prevention and control.

Participants also mentioned extrinsic challenges that directly influence the strength and impact of local leadership in the DR's most vulnerable communities. Despite the existence of nongovernmental organizations with social missions, dual challenges exist in dengue prevention and control. First, MISPAS has allocated economic resources for the integrated rollout of health interventions during dengue epidemics, at the expense of local and national infrastructure for public health preparedness. A prompt public health response to epidemics, without appropriate preparedness, can imperil the ability to withstand future emerging disease epidemics.[41] Second, with limited followup, training opportunities, and professional incentives in local leadership, HWs may be apathetic and perceive their stakeholder role in decision-making as unimportant.[42] In turn, this low morale may lead HWs to pursue employment outside of the local community, in national or international agencies that can provide financial stability and career advancement.

Participants described a panorama of inadequate sustainable community participation in dengue control action, driven by four primary intrinsic and extrinsic factors. At the time of this study, there were no regulations in place to empower communities to develop the necessary leadership to conduct health initiatives. An understanding of the influence of these intrinsic and extrinsic factors can inform DR health authorities' discussions of steps to increase community participation in regular and sustainable dengue initiatives, including increased political commitment to expand health education and strengthen dengue surveillance programs.

As in other Latin American and Caribbean nations, the DR's national health system has undergone reforms aimed at strengthening health care service delivery to all DR citizens; the process was initiated in 2002.[43] In this transition, they have faced limitations in economic and health sectors, including 1) fluctuating economic situations amidst a national economic crisis in 2003 and an international economic crisis in 2008; 2) epidemiologic transition with emergence of noncommunicable diseases as a major population health problem; and 3) continued failure to meet targets for basic health indicators (e.g., life expectancy and infant mortality) and health equity.[43] In national and regional dialogue to strengthen dengue control strategies, health authorities have proposed steps to enhance capacity building and quality control in six components: clinical diagnosis and management, entomology, environmental health, epidemiology, health promotion and laboratory evaluation.[18] Activities proposed by PAHO related to health promotion include building intersectoral collaborations among agencies or organizations, increasing capacity building for health care workers, and establishing research capacity through monitoring and evaluation processes; but strategies to enhance incentives, expertise and leadership development among HWs have tended to be overlooked.[18]

Dengue epidemics have occurred every three to five years in many Latin American and Caribbean nations,[44] and public health preparedness for dengue prevention and control strategies remains key for reduced disease transmission (and consequently morbidity and mortality rates). With increased attention to health inequities related to social determinants of health across the Americas Region,[45] national dengue initiatives should highlight the One Health approach, where transdisciplinary collaborations can focus on interactions between human, animal and environmental health.[46]

For this study, semistructured interviews were ideal for eliciting HWs perceived challenges for adherence to dengue prevention 
and control measures in diverse rural and urban DR communities. As future steps, however, focus group discussions may provide further insight into the complex and interconnected factors that influence adherence to recommended vector control practices. In turn, these insights may lead to new local and national policies in vector control practices that integrate, encourage and build on enhanced moral responsibility and solidarity among community members.

This study has some limitations. First, participants were selected from municipalities in five DR provinces located in the northand south-central geographic regions and thus findings might not be generalizable across the DR. However, since dengue is endemic throughout the $D R$, variation within or between sites, and differences from the eastern and western provinces not included, may not be meaningful. Second, data collection was completed one year after a major dengue outbreak, suggesting increased awareness and community mobilization at the time, due to a national call to action. However, since HWs are familiar with their daily practice in dengue prevention and control, recall bias may have been minimized. Third, only two researchers participated in data collection and analysis, so we understand that other data interpretations are possible.[47] However, peer debriefing with a panel of experts provided indispensable feedback on the four emerging themes for this study. The addition of a rank order of these four themes, based on perceived individual contribution to dengue prevention and control, might strengthen future dengue action at the community and national levels.

\section{CONCLUSIONS}

HWs perceived challenges for dengue prevention and control in the DR reflect the complex interplay of economic, environmental, health, political and social factors that can directly or indirectly influence individual and community adherence to recommended prevention measures. By better understanding how these intrinsic and extrinsic factors hinder adherence, health system authorities can revise national policies to strengthen community participatory action in vector control, empower leadership potential among HWs and community members, and provide an appropriate systemic approach to prevention of disease transmission. Transdisciplinary health collaborations for vector control and prevention will be essential to develop sustainable dengue prevention and control initiatives in low-resource settings such as the DR.

\section{ACKNOWLEDGMENTS}

The authors thank study participants for sharing their experiences and views of dengue prevention and control in the DR. We also acknowledge peer debriefing provided by academic professors and clinicians at the Universidad Católica Tecnológica del Cibao School of Medicine and the HRUJMCB Department of Epidemiology during data analysis. -1/

\section{APPENDIX 1: INTERVIEW QUESTIONS}

I. Occupational experiences in dengue prevention and control 1. How would you describe your daily work routine regarding dengue prevention and control in the community?

II. Views on dengue prevention and control in communities 2. How would you describe the general level of concern in the community about dengue as a health problem?

3. How do citizens use protection methods against mosquitoes in the community?

4. Describe an example of when and why citizens used protection methods against mosquitoes in the community.

III. Perceived challenges related to reduced citizens' adherence to recommended prevention measures

5. Describe an example of when and why citizens did not use protection methods against mosquitoes in the community. 6 . Why do you think that some people protect themselves against mosquitoes while others do not?

7. Do you think that someone who has had dengue is more likely to use protection against mosquitoes than someone who has not? Why?

8. Do you think that someone who knows more people who have had dengue is more likely to use protection against mosquitoes than someone who knows fewer or no people who have had dengue? Why?

9. What do you believe can be done to improve adherence to vector control practices in your community and in the DR?

\section{REFERENCES}

1. World Health Organization. Global strategy for dengue prevention and control, 2012-2020. Geneva: World Health Organization; 2012 Aug. 43 p.

2. Bhatt S, Gething PW, Brady OJ, Messina JP, Farlow AW, Moyes CL, et al. The global distribution and burden of dengue. Nature. 2013 Apr;496(7446):504-7.

3. Brady OJ, Gething PW, Bhatt S, Messina JP, Brownstein JS, Hoen AG, et al. Refining the global spatial limits of dengue virus transmission by evidence-based consensus. PLoS Negl Trop Dis. 2012 Aug 7:6(8):e1760.

4. Diamond MS, Harris E, Ennis FA. Defeating dengue: a challenge for a vaccine. Nat Med. 2012 Nov;18(11):1622-3.

5. Morrison AC, Zielinski-Gutierrez E, Scott TW, Rosenberg R. Defining challenges and proposing solutions for control of the virus vector Aedes aegypti. PLoS Med. 2008 Mar:5(3):e68.

6. Tapia-Conyer R, Betancourt-Cravioto M, Méndez-Galván J. Dengue: an escalating public health problem in Latin America. Paediatr Int Child Health. 2012 May;32 Suppl 1:14-7.

7. Gratz NG, Steffen R, Cocksedge W. Why aircraft disinsection? Bull World Health Org. 2000;78(8):995-1004.
8. Lounibos LP. Invasions by insect vectors of human disease. Annu Rev Entomol. 2002;47:233-66.

9. Gubler DJ. Dengue, urbanization and globalization: the unholy trinity of the 21 st century. Trop Med Health. 2011 Dec;39(4 Suppl):3-11.

10. Kyle JL, Harris E. Global spread and persistence of dengue. Annu Rev Microbiol. 2008 Oct 13;62:71-92.

11. Spiegel J, Bennett S, Hattersley L, Hayden $\mathrm{MH}$, Kittayapong P, Nalim S, et al. Barriers and bridges to prevention and control of dengue: the need for a social-ecological approach. Eco Health. 2005 Dec;2(4):273-90.

12. Parks $\mathrm{W}$, Lloyd L. Planning social mobilization and communication for dengue fever prevention and control: a step-by-step guide. Geneva: World Health Organization; 2004. 138 p

13. Guzmán MG. Thirty years after the Cuban dengue hemorrhagic epidemic of 1981. MEDICC Rev. 2012 Apr;14(2):46-51

14. Drexler A, editor. Handbook for integrated vector management. Geneva: World Health Organization; 2012 Jun. 67 p.

15. Lehmann U, Sanders D. Community health workers: what do we know about them? Ge- neva: World Health Organization; 2007 Jan. $34 \mathrm{p}$.

16. The World Bank [Internet]. Washington, D.C.: The World Bank; c2017. Dominican Republic; 2016 [cited 2017 Mar 5]. Available from: http:// data.worldbank.org/country/dominican-republic

17. Whiteford LM. The ethnoecology of dengue fever. Med Anthropol Q. 1997 Jun;11(2):202-23.

18. Pan American Health Organization; Ministry of Public Health (DO). Informe final: estrategia nacional de gestión integrada de prevención y control del dengue, República Dominicana [Internet]. Santo Domingo (DO): Ministry of Public Health (DO); 2004 Nov [cited 2017 Apr 1]. Available from: http://www.paho.org/dor/index.php?option=com docman\&view=download\&category_slug= prevencion-y-control-de-enfermedades-1\&alias $=46$-estrategia-nacional-de-gestion-integrada -de-prevencion-y-control-del-dengue-2004\&Item $i d=273$. Spanish

19. Ministry of Public Health (DO). Dirección General de Epidemiología. Alerta epidemiológica No. 2 [Internet]. Santo Domingo (DO): Ministry of Public Health (DO); 2013 [cited 2017 Mar 5]. Available from: http://digepisalud.gob.do/docs/ Vigilancia\%20Epidemiologica/Alertas $\% 20$ epi 
demiologica/Dengue/Nacional/Alerta\%20Den gue\%20agosto\%202013.pdf. Spanish.

20. Ministry of Public Health (DO). Normas nacionales para la vigilancia epidemiológica de enfermedades transmisibles y otros eventos. Serie de Normas Nacionales No. 11. Santo Domingo (DO): Ministry of Public Health (DO); 1998. 460 p. Spanish.

21. Chapman HJ. Holistic approach in preventing spread of infectious diseases: a Cuban example. Perspect Public Health. 2016 Jul 1;136(4):189.

22. Ministry of Health Buenos Aires; United Nations Children's Fund. Participación social en la prevención, del dengue, zika y chikungunya: adaptación de la guía para el promotor. 3rd ed [Internet]. New York: United Nations Children's Fund; 2016 [cited 2017 Mar 25]. Available from: https://www.unicef.org/argentina/spanish/salud _MANUAL_DENGUE_A5-Version2016_web .pdf. Spanish.

23. Wichmann O, Vannice K, Asturias EJ, de Albuquerque Luna EJ, Longini I, López AL, et al. Live-attenuated tetravalent dengue vaccines: the needs and challenges of post-licensure evaluation of vaccine safety and effectiveness. Vaccine. 2017 Oct 9;35(42):5535-42.

24. Creswell JW, Poth CN. Qualitative inquiry and research design: choosing among five approaches. 4th ed. Thousand Oaks (US): Sage Publications, Inc.; 2017 Jan 25. 488 p.

25. McLeroy KR, Bibeau D, Steckler A, Glanz K. An ecological perspective on health promotion programs. Health Educ Q. 1988 Winter;15(4):351-77.

26. Skinner CS, Tiro J, Champion VL. The health belief model. In: Glanz K, Rimer BK, Viswanath $\mathrm{K}$, editors. Health behavior: theory, research, and practice. 5th ed. San Francisco (US): JosseyBass; 2015. p. 75-94.

27. Bernard HR. Research methods in anthropology: qualitative and quantitative approaches. 5th ed. Lanham (US): AltaMira Press; 2011 May 16. 680 p.

28. Charmaz K. Constructing grounded theory. 2nd ed. Los Angeles: Sage Publications Inc.; 2014 Apr $9.416 \mathrm{p}$

29. Ryan GW, Bernard HR. Techniques to identify themes. Field Methods. 2003 Feb 1;15(1):85-109.

30. Sandelowski M, Barroso J. Classifying the findings in qualitative studies. Qual Health Res. 2003 Sep;13(7):905-23.

31. Lincoln YS, Guba EG. Naturalistic inquiry. 1st ed. Newbury Park (US): Sage Publications; 1985 Apr. $416 \mathrm{p}$.

32. Pimentel R, Skewes-Ramm R, Moya J. Chikungunya en la República Dominicana: lecciones aprendidas en los primeros seis meses. Rev Panam Salud Pública. 2014 Nov;36(5):336-41. Spanish.

33. Fauci AS, Morens DM. Zika virus in the Americas - yet another arbovirus threat. N Engl J Med. 2016 Feb 18;374(7):601-4.

34. Muñoz M, Navarro JC. Virus mayaro: un arbovirus reemergente en Venezuela y Latinoamérica. Biomédica. 2012;32(2):286-302. Spanish.

35. Ministry of Public Health (DO). Informe de situación de salud de la República Dominicana, 2003 [Internet]. Santo Domingo (DO): Ministry of Public Health (DO); 2006 [cited 2017 Apr 1]. Available from: http://digepisalud.gob.do/docs/ Analisis $\% 20$ de $\% 20$ Situacion/Informe $\% 20$ de $\% 20$ Situacion $\% 20$ de $\% 20$ Salud/Informe $\% 20$ de $\% 20$ Salud\%202003.pdf. Spanish.

36. Georges AS, Mehra V, Scott K, Sriram V. Community participation in health systems research: a systematic review assessing the state of research, the nature of interventions involved and the features of engagement with communities. PLoS One. 2015 Oct 23;10(10):e0141091.

37. Atkinson JA, Vallely A, Fitzgerald L, Whittaker $M$, Tanner M. The architecture and effect of participation: a systematic review of community participation for communicable disease control and elimination. Implications for malaria elimination. Malar J. 2011 Aug 4;10:225.

38. Wong LP, AbuBakar S. Health beliefs and practices related to dengue fever: a focus group study. PLoS Negl Trop Dis. 2013 Jul 11;7(7):e2310.

39. Suárez R, González C, Carrasquilla G, Quintero $J$. An ecosystem perspective in the socio-cultural evaluation of dengue in two Colombian towns. Cad Saúde Pública. 2009;25 Suppl 1:S104-14.

40. World Health Organization. Dengue: guidelines for diagnosis, treatment, prevention and control: new edition. Geneva: World Health Organization; 2009. 147 p.

41. Institute of Medicine, Board on Global Health, Committee on Emerging Microbial Threats to Health in the 21st Century. Microbial threats to health: emergence, detection, and response. 1st ed. Smolinski MS, Hamburg MA, Lederberg J, editors. Washington, D.C.: National Academies Press; 2003 Aug 25. $398 \mathrm{p}$

42. Willis-Shattuck M, Bidwell P, Thomas S, Wyness L, Blaauw D, Ditlopo P. Motivation and retention of health workers in developing countries: a systematic review. BMC Health Serv Res. 2008 Dec 4;8:247.

43. Rathe M. Dominican Republic: Can universal coverage be achieved? Background Paper, 10 [Internet]. Geneva: World Health Organization;
2010 [cited 2017 Jan 21]. 19 p. Available from: http://www.who.int/healthsystems/topics/finan cing/healthreport/DRNo10FINALV2.pdf

44. Gómez-Dantés H, Willoquet JR. Dengue in the Americas: challenges for prevention and control. Cad Saúde Pública. 2009;25 Suppl 1:S19-31.

45. Pan American Health Organization; World Health Organization. Últimos adelantos técnicos en la prevención y control del dengue en la Región de las Américas, 2014 [Internet]. Washington, D.C.: World Health Organization; 2014 [cited 2017 Apr 9]. Available from: http://www2.paho.org/hq/ index.php?option $=$ com docman\&task=doc view \&ltemid=270\&gid=27234\&lang=es. Spanish .

46. World Health Organization. One Health [Internet]. Geneva: World Health Organization; 2017 Sept [cited 2017 Oct 5]. Available from: http://www.who .int/features/qa/one-health/en/

47. Miles MB, Huberman AM, Saldaña J. Qualitative data analysis: a methods sourcebook. 3rd ed. Thousand Oaks (US): Sage Publications, Inc.; 2013 Apr 18. 408 p.

\section{THE AUTHORS}

Bienvenido A. Veras-Estévez, physician specializing in epidemiology, with a master's degree in public health. Team leader, Department of Research, Universidad Católica Tecnológica del Cibao Faculty of Health Sciences, La Vega, Dominican Republic. Research manager, Department of Epidemiology and Statistics, Hospital Regional Universitario José María Cabral y Báez, Santiago de los Caballeros, Dominican Republic.

Helena J. Chapman (Corresponding author: hchapman@ufl.edu), physician specializing in public health, with a master's degree in public health (epidemiology) and doctorate in public health (One Health). Department of Environmental and Global Health, University of Florida College of Public Health and Health Professions (UF PHHP), Gainesville, Florida, USA. This research was conducted while the author was a graduate student in the Department of Epidemiology at the UF PHHP.

Submitted: April 21, 2017

Approved for publication: September 23, 2017 Disclosures: None 